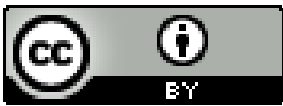

\title{
ACESSO E PERMANÊNCIA NA EDUCAÇÃO SUPERIOR: PERCEPÇÕES DE ESTUDANTES QUILOMBOLAS NA BAIXADA MARANHENSE
}

\author{
Dinalva Pereira Goncalves ${ }^{1}$ \\ Evandicleia Ferreira De Carvalho ${ }^{2}$ \\ Ana Patricia Dos Santos Sodré
}

Resumo: O presente estudo tem por objetivo refletir sobre as condições de acesso e permanência de estudantes quilombolas na educação superior, através de análise das percepções de beneficiários do Programa Bolsa Permanência do Ministério da Educação - PBP/MEC, do Campus de Pinheiro da Universidade Federal do Maranhão (UFMA), oriundos de comunidades quilombolas. Discute as políticas de acesso e permanência na educação superior, situando a assistência estudantil como importante ferramenta para o combate à evasão e retenção na universidade. Descreve dados referentes ao perfil básico e acadêmico de estudantes quilombolas desse Campus universitário, beneficiários do PBP/MEC, além de elucidar a visão dos próprios sujeitos da pesquisa sobre acesso e permanência de quilombolas na educação superior. A metodologia aplicada tomou por base pesquisas bibliográficas, questionários estruturados, análise do perfil básico e acadêmico dos estudantes beneficiários do PBP/MEC no Campus Pinheiro/UFMA. A partir dos estudos e dados coletados, identificou-se que esses estudantes são, na maioria, oriundos do ensino público e ingressantes por sistema de cotas em cursos de licenciatura. Verificou-se também que as trajetórias na universidade apresentam desafios de ordem socioeconômica e acadêmica, porém registram baixos percentuais de evasão e elevado rendimento acadêmico entre os bolsistas.

Palavras-Chave: Acesso e permanência. Educação superior. Estudantes quilombolas.

\section{ACCESS AND PERMANENCE IN HIGH EDUCATION: PERCEPTIONS OF QUILOMBOLA STUDENTS IN BAIXADA MARANHENSE}

\footnotetext{
1 Mestra em Educação/PPGEEB/UFMA. Técnica em Assuntos Educacionais do Campus Pinheiro da Universidade Federal do Maranhão. E-mail: dinalva.pg@ufma.br

2 Mestra em Educação/PPGE/UFMA. Pedagoga do Campus Pinheiro da Universidade Federal do Maranhão. E-mail: evandicleia.carvalho@ufma.br

${ }^{3}$ Especialista em Gestão Pública/UFMA. Técnica em Assuntos Educacionais do Campus Pinheiro da Universidade Federal do Maranhão. E-mail: aps.sodre@ufma.br
} 


\begin{abstract}
This study aims to reflect about the conditions of access and permanence of quilombola students in high education, by analyzing the perceptions of students from the Permanent Scholarship Program of the Ministry of Education - PBP / MEC, at the Federal University of Maranhão (UFMA) Pinheiro Campus, who come from quilombola communities. It discusses the policies of access and permanence in high education, placing student assistance as an important tool to avoid dropout and retention in the university. It describes data related to the quilombola students' basic and academic profile at this university campus, students from the PBP / MEC, besides it elucidates the view of the research subjects themselves about the access and permanence of quilombolas in high education. The methodology applied was based on bibliographic research, structured questionnaires, analysis of students' basic and academic profile benefiting from the PBP / MEC Pinheiro Campus / UFMA. Starting from the studies and data collected, it was identified that most of these students come from public education and entered by quota system in undergraduate courses. It was also verified that their way in the university present socioeconomic and academic challenges, however they register low dropout percentages and high academic performance among the scholarship holders.
\end{abstract}

Keywords: Access and permanence. High education. Quilombola students.

\title{
ACCESO Y PERMANENCIA EN LA EDUCACIÓN SUPERIOR: PERCEPCIONES DE ESTUDIANTES QUILOMBOLAS EN LA REGIÓN DE LA BAIXADA MARANHENSE
}

Resumen: El presente estudio tiene por objetivo reflexionar sobre las condiciones de acceso y permanencia de estudiantes quilombolas en la educación superior, a través de análisis de las percepciones de beneficiarios del Programa Bolsa Permanencia del Ministerio de la Educación - PBP/MEC, del Campus de la ciudad de Pinheiro Estado de Maranhão de la Universidad Federal do Maranhão (UFMA), oriundos de comunidades quilombolas. Discute las políticas de acceso y permanencia em la educación superior, situando la asistencia estudiantil como importante herramienta para el combate a la evasión y retención en la universidad. Describe datos referentes al perfil básico y académico de estudiantes quilombolas de ese Campus universitario, beneficiarios del PBP/MEC, además de elucidar la visión de los propios sujetos de la investigación sobre acceso y permanencia de quilombolas en la educación superior. La metodología aplicada tomó por base investigaciones bibliográficas, cuestionarios estructurados, análisis del perfil básico y académico de los estudiantes beneficiarios del PBP/MEC en el Campus Pinheiro/UFMA. A partir de los estudios y datos colectados, se identificó que esos estudiantes son, en la mayoría, oriundos de la enseñanza pública e ingresantes por sistema de cuotas en cursos de licenciatura. Se verificó también que las trayectorias en la universidad presentan desafíos de orden socioeconómica y académica, pero registran bajos porcentuales de evasión y elevado rendimiento académico entre los becados.

Palabras-Clave: Acceso y permanencia. Educación superior. Estudiantes quilombolas.

\section{ACCÈS ET PERMANENCE DANS L'ENSEIGNEMENT SUPÉRIEUR: PERCEPTIONS DES ETUDIANTS QUILOMBOLA A BAIXADA MARANHENSE}


Résumé: Cette étude vise à réfléchir sur les conditions d'accès et de permanence des étudiants quilombolas dans l'enseignement supérieur, en analysant les perceptions des bénéficiaires du Programme Bourses de Permanence du Ministère de l'Éducation - PBP / MEC, du Campus Pinheiro de l'Université Fédérale du Maranhão (UFMA), provenant des communautés de quilombolas. Il examine les politiques d'accès et de permanence dans l'enseignement supérieur, plaçant l'aide aux étudiants comme un outil important pour lutter contre le décrochage et la rétention à l'université. Il décrit les données relatives au profil de base et académique des étudiants quilombolas de ce campus universitaire, bénéficiaires du PBP / MEC, et élucide le point de vue des sujets de recherche eux-mêmes sur l'accès et la permanence des quilombolas dans l'enseignement supérieur. La méthodologie appliquée à été basée sur des recherches bibliographiques, des questionnaires structurés, une analyse du profil de base et académique des étudiants bénéficiant du Campus PBP / MEC Pinheiro / UFMA. À partir des études et des données collectées, il a été identifié que ces étudiants sont pour la plupart issus de l'enseignement public et inscrits par système de quotas dans les cours de premier cycle. Il a également été vérifié que les trajectoires dans l'université présentent des défis socioéconomiques et académiques, mais enregistrent de faibles pourcentages d'abandon et de bons résultats scolaires parmi les boursiers.

Mots-clés: Accès et permanence. Enseignement supérieur. Étudiants Quilombolas.

\section{INTRODUÇÃO}

A partir de meados dos anos 2000, no Brasil, com a adoção de políticas públicas expansionistas pelo Governo Federal, registra-se a ampliação de vagas e matrículas em Instituições Federais de Ensino Superior, além da criação de novas universidades, expansão e interiorização de outras já existentes ${ }^{4}$ em várias regiões do país. Essas políticas foram responsáveis pela ampliação das oportunidades de acesso ao ensino superior e pela adoção de ações afirmativas e de permanência estudantil que, apesar de limitadas, vêm promovendo maior participação dos grupos sociais, historicamente desfavorecidos e até excluídos, no contexto acadêmico.

Esse cenário, ilustrado por lutas sociais e universalização do direito à educação, representa repercussões de políticas como o Programa de Apoio a Planos de Reestruturação e Expansão das Universidades Federais (REUNI) - Decreto nº 6096/2007,

\footnotetext{
${ }^{4}$ De acordo com dados do Ministério da Educação, na graduação presencial das instituições federais, houve um crescimento equivalente a $60 \%$, entre os anos de 2003 a 2011. Esse processo foi acompanhado do expressivo aumento do número de universidades e expansão de outras, elevando o quantitativo de municípios atendidos pelas IFES (MEC/INEP, 2012). Já entre 2006 e 2016, esse aumento firmou-se em $62,8 \%$, com uma média anual de $5 \%$ de crescimento (MEC/INEP, 2017).
} 
medida expansionista e reformadora que impulsionou a interiorização das universidades públicas, alcançando, dessa forma, um maior contingente populacional, principalmente nas regiões descentralizadas dos grandes polos urbanos.

Outra mudança importante foi promovida pela Lei $n^{\circ} 12.711 / 12$, conhecida como Lei de Cotas, que estabelece reserva mínima de 50\% das vagas das instituições federais a estudantes oriundos do ensino médio público, com atenção para as famílias com renda per capta de até um salário mínimo e meio (Brasil, 2012a). Esta medida, embora tenha um caráter compensatório, representa um reparo à dívida social para com os pobres, negros e outros grupos historicamente excluídos na sociedade.

A partir desse processo de ampliação e do desenvolvimento de políticas de ações afirmativas no interior das instituições, um maior número de pessoas tem alcançado a educação superior, o que vem ocasionando uma diversificação do perfil do estudante universitário.

Nesse contexto, a defesa por políticas de assistência estudantil ganha maior notoriedade, uma vez que se fez necessário garantir, além do acesso, a permanência desses grupos que adentraram nos espaços acadêmicos. Como parte das ações da Política Nacional de Assistência Estudantil, é criado o Programa Nacional de Assistência Estudantil (PNAES), por meio do Decreto $\mathrm{n}^{\mathrm{o}} 7.234 / 2010$, com o objetivo de promover e ampliar as condições de permanência dos jovens na educação superior pública federal (Brasil, 2010).

Concretizando mais uma ação da Política Nacional de Assistência Estudantil, foi criado, em 2013, o Programa Bolsa Permanência (PBP), financiado pelo Ministério da Educação (MEC), através do Fundo Nacional de Desenvolvimento da Educação (FNDE). Tal iniciativa visava à concessão de auxílio financeiro a estudantes matriculados em Instituições Federais de Ensino Superior em situação de vulnerabilidade socioeconômica e a estudantes indígenas e quilombolas (Brasil, 2013).

A Universidade Federal do Maranhão (UFMA), no ano de 2016, registrou o quantitativo de 17.919 matrículas, dentre estas, 2.132 vagas foram distribuídas em oito campi do continente: Bacabal, Balsas, Chapadinha, Codó, Grajaú, Imperatriz, São Bernardo e Pinheiro (UFMA, 2017a). Especificamente no Campus de Pinheiro/UFMA, a expansão tem sido bastante evidente, tanto que, no ano de 2016, essa unidade acadêmica já dispunha de 07 cursos regulares de graduação: Ciências Humanas - História; Ciências 
Humanas - Filosofia; Ciências Naturais - Biologia; Educação Física; Enfermagem; Engenharia da Pesca e Medicina (UFMA, 2019). Constituem o corpo discente local, jovens e adultos da região da Baixada Maranhense, de outras regiões do estado do Maranhão, bem como de outros estados da Federação. Em muitos casos, são estudantes com realidades socioeconômicas desfavoráveis que buscam no serviço de assistência estudantil meios para auxiliar, quando não custear totalmente, as despesas relacionadas ao curso.

Entre os anos de 2013 e o $1^{\circ}$ semestre de 2019, registrou-se a inclusão de 38 estudantes quilombolas do Campus Pinheiro/UFMA no Programa Bolsa PermanênciaPBP/MEC (UFMA, 2019). A maioria deles é oriunda de municípios dos arredores de Pinheiro, região com expressiva concentração de comunidades quilombolas no estado do Maranhão.

Diante do exposto, este estudo tem por objetivo refletir sobre as condições de acesso e permanência de estudantes quilombolas na educação superior, analisando as percepções de beneficiários do PBP/MEC, do Campus Pinheiro/UFMA, oriundos de comunidades quilombolas. Para uma fundamentação teórica, discutem-se as políticas de acesso e permanência na educação superior, situando a assistência estudantil como importante ferramenta para o combate à evasão e retenção na universidade. Além disso, o presente trabalho elucida a visão de alguns desses sujeitos sobre a importância da educação superior em suas vidas e as dificuldades enfrentadas para prosseguir os estudos e desenvolverem-se enquanto estudantes universitários. Para tanto, utilizamos como metodologia, pesquisas bibliográficas e questionários, além da análise do perfil básico e acadêmico desses estudantes, a partir de informações do Sistema Integrado de Gestão de Atividades Acadêmicas (SIGAA) da Universidade Federal do Maranhão.

\section{POLÍTICA DE EXPANSÃO DAS UNIVERSIDADES BRASILEIRAS E DEMOCRATIZAÇÃO DO ACESSO AO ENSINO SUPERIOR}

No processo de expansão da Educação Superior engendrado no Brasil, a partir de meados dos anos 2000 - que corresponde ao período de ampliação do sistema federal - registra-se uma fase de desenvolvimento de políticas públicas compensatórias e de democratização na universidade pública brasileira que, apesar dos limites, impulsionou a 
ampliação de campi e cursos, permitindo o acesso de minorias sociais e a prática de iniciativas voltadas à permanência estudantil. Esse crescimento foi impulsionado, especialmente, pela implementação de medidas normativas regulatórias e de expansão que estimulavam a descentralização de campi universitários e reparos da dívida do país com os estudantes oriundos de grupos sociais desprivilegiados.

No âmbito do setor federal, com a criação do Programa Expandir, durante o governo do presidente Luís Inácio Lula da Silva (2003-2010), o Ministério da Educação destinou recursos à criação de novos campi, especialmente em municípios do interior do país (Brasil /MEC, 2005). Na sequência, no ano de 2007, foi instituído o Programa de Apoio a Planos de Reestruturação e Expansão das Universidades Federais - REUNI, pelo Decreto $\mathrm{n}^{\mathrm{o}} 6.096$ de 2007, dando continuidade e ampliando as ações de expansão/interiorização.

O REUNI foi lançado como política de valorização do setor público federal e tinha por objetivo ampliar as condições de acesso e permanência nas universidades federais, a nível de graduação (Brasil, 2007). O Programa possuía duas metas principais: “[...] a elevação gradual da taxa de conclusão média dos cursos de graduação presenciais para noventa por cento e da relação de alunos de graduação em cursos presenciais por professor para dezoito, ao final de cinco anos, a contar do início de cada plano" (Brasil, 2007, s/p). Com tais medidas, pretendia-se ampliar o acesso à educação superior pública e revitalizar a infraestrutura das instituições, que se encontravam deterioradas, após período de restrição do orçamento das universidades federais.

De acordo com documento publicado pelo MEC no ano de 2012, houve uma expressiva expansão do acesso à educação superior durante o período de implantação dos Programas Expandir e REUNI. Em decorrência deles, foram criadas 14 Universidades Federais e 125 novos campi, no país, entre os anos de 2005 a 2010. Na graduação presencial, no período de 2007 a 2011, a expansão foi de mais de 90 mil vagas nestas Instituições de Ensino Superior (IES). E na pós-graduação, houve um incremento de mais de 30 mil matrículas no mesmo período (Brasil /MEC, 2012b).

Mais adiante, durante o governo da presidenta Dilma Rousseff (2011-2016), cabe sublinhar a criação da Lei ${ }^{0}$ 12.711, de 29 de agosto de 2012, que trata sobre o ingresso nas universidades federais e nas instituições federais de ensino técnico de nível médio, estabelecendo reserva mínima de $50 \%$ de vagas a estudantes oriundos do ensino 
público, com atenção àqueles advindos de famílias com renda de até 1,5 salário mínimo (Brasil, 2012a).

No ensino superior público, a modalidade de políticas de cotas é a mais relevante, porém as ações afirmativas não se restringiram apenas aos espaços públicos, visto que há outras modalidades hoje em vigência no ensino superior privado no Brasil. Como exemplos, citam-se o Programa Universidade para Todos (Prouni) e o Fundo de Financiamento Estudantil (FIES). Estes programas visam, respectivamente, garantir bolsas integrais e parciais; e financiar, em parte ou no todo, os custos com cursos de graduação em instituições privadas de ensino superior.

Embora tais medidas não fossem capazes de alterar todo o processo de exclusão educacional, responderam às lutas por mais oportunidades de acesso e contribuíram para compensar a histórica desigualdade imposta aos segmentos mais vulneráveis da população, em relação ao acesso à educação superior.

Dentre esses segmentos, destacamos os negros, formados em parte por sujeitos oriundos de comunidades remanescentes de quilombos, historicamente excluídos do acesso à educação. Atualmente, a partir da implementação de tais políticas, é possível verificar maior presença de estudantes quilombolas nos espaços universitários, sendo essa conquista fruto de lutas seculares.

\section{QUILOMBOLAS NA EDUCAÇÃO SUPERIOR: POLÍTICAS DE PERMANÊNCIA, LUTAS E DESAFIOS}

É inegável que a elevação do número de vagas em instituições públicas vem representando uma importante conquista para a sociedade brasileira, especialmente para grupos sociais desfavorecidos, mas cabe ressaltar que este é apenas um passo na longa trajetória rumo à democratização do direito à educação. Isso porque, além do acesso, é indispensável garantir aos estudantes em situações socioeconômicas desfavoráveis as condições para permanência e conclusão dos estudos.

Ao longo da década de 1990, várias medidas foram tomadas no combate à discriminação racial no país, a exemplo da aprovação da Lei de Diretrizes e Bases da Educação Nacional (LDBEN), Lei $n^{\circ}$ 9.394/96, que contou com contribuições das diferentes etnias. Posteriormente, entra no cenário das políticas educacionais, a 
possibilidade de reserva de vagas para negros no ensino superior das universidades públicas. A Universidade de Brasília (UnB) foi a primeira instituição a adotar o sistema de cotas para negros, incluindo-o em seu vestibular do ano de 2003. Aos poucos, outras universidades públicas foram aderindo ao sistema.

Vale também destacar que, a partir da criação da Secretaria Especial de Políticas de Promoção da Igualdade Racial (SEPPIR), em 2003, houve maior abertura para participação do Movimento Negro nas discussões e formulações de políticas públicas voltadas para a população negra. Concentraram-se esforços no sentido de institucionalizar medidas de ação afirmativa por meio da criação de programas, leis e decretos; além de testemunhar-se intensa negociação entre as instituições do Estado, o Movimento Negro, os Pré-Vestibulares Comunitários, a academia, a mídia e a sociedade civil acerca das questões raciais e a busca por estratégias de solução para os problemas apresentados (Jr. e Daflon, 2015).

Graças a esses dispositivos está sendo possível uma ampliação no ingresso de estudantes das camadas desfavorecidas, entre elas, os oriundos de comunidades quilombolas. Contudo, embora represente um grande avanço em matéria de acesso ao ensino superior, não tem sido plenamente satisfatório, porquanto não garante que, após o alcance da vaga na instituição, as condições de permanência sejam supridas para efeito de conclusão do curso.

As cotas sociais e raciais facilitaram o acesso à universidade; porém, para os estudantes quilombolas, outras barreiras surgem como a falta de condições financeiras para se manterem em outra cidade, os custos com transporte, alimentação, material de estudos etc. Nesse sentido, destaca-se a importância das políticas de permanência nas universidades.

Desse modo, poderíamos refletir sobre a importância das políticas de permanência (e assistência). Estudantes menos privilegiados não podem contar com a família (ou contam de forma reduzida) para os apoiarem nas demandas surgidas em função de uma escolarização prolongada. Assim, acabam tendo que criar suas próprias práticas e estratégias ou contar com eventuais mecanismos institucionais de apoio à sua permanência no ambiente universitário e/ou para assisti-los na oferta de algum recurso (HONORATO et al, 2014, p. 07).

Como se vê, a dificuldade de permanência de grupos desfavorecidos, como os quilombolas, na educação superior, remete às desigualdades desenhadas historicamente 
pelo processo de exclusão social. É notório que um novo círculo vicioso possa ser engendrado nesse processo, uma vez que esses indivíduos não conseguem permanecer na Universidade por serem demasiadamente pobres e não vislumbram meios para sair da condição de extrema pobreza por não terem alcançado oportunidades no mundo do trabalho que só a academia é capaz de proporcionar.

Nesse contexto, a permanência no ensino superior é um dos grandes desafios das universidades, o que clama, na maioria das vezes, por políticas de assistência estudantil, sobretudo, nos casos de estudantes oriundos de segmentos sociais desfavorecidos e excluídos, tendo, como exemplo, os quilombolas.

Conforme exposto anteriormente, entre as ações da Política Nacional de Assistência Estudantil, destaca-se a criação do Programa Nacional de Assistência Estudantil (PNAES) - Decreto $n^{\circ} 7.234 / 2010$, o qual tem como objetivos: democratizar as condições de permanência na educação superior; minimizar os efeitos das desigualdades sociais e regionais; reduzir as taxas de retenção e evasão; e contribuir para a promoção da inclusão social pela educação (Brasil, 2010).

Importa reforçar também como ação da Política Nacional de Assistência Estudantil, o Programa Bolsa Permanência (PBP) do Ministério da Educação (MEC), criado no ano de 2013, como "fruto de esforço coletivo com os parceiros, assim como do engajamento daqueles que assumiram o compromisso com a democratização do acesso e da permanência no ensino superior gratuito no país, sobretudo de indígenas, quilombolas e estudantes de baixa renda" (Brasil, 2013, p.5). Este programa surge em função das pressões dos movimentos sociais, como forma de garantir não só o acesso como também a permanência e a diplomação dos estudantes em situação de vulnerabilidade socioeconômica, com atenção especial aos indígenas e quilombolas ${ }^{5}$.

Dias Sobrinho, em sua análise sobre a problemática, chama a atenção para o fato de que,

[...] além da expansão das matrículas e da inclusão social de jovens tradicionalmente desassistidos, em razão de suas condições econômicas, preconceitos e outros fatores, é imprescindível que lhes sejam assegurados

\footnotetext{
${ }^{5}$ O Programa Bolsa Permanência tem garantido, desde 2013, a concessão de auxílio financeiro diferenciado a estudantes indígenas e quilombolas (sem necessidade de seleção, apenas comprovação de preenchimento dos requisitos). Refere-se a um dos mecanismos que tem oferecido as maiores condições de permanência desse público nas instituições de ensino superior.
} 
também os meios de permanência sustentável, isto é, as condições adequadas para realizarem com boa qualidade os seus estudos (DIAS SOBRINHO, 2010, p. 126).

Nesse aspecto, a democratização da educação superior não se limita à ampliação de oportunidades de acesso, mas necessita de medidas mais amplas e profundas, de modo que haja garantias para a clientela contemplada por tais oportunidades. Destarte, no que se refere às políticas de expansão, cumpre analisar a articulação com políticas de assistência estudantil que considerem as especificidades dos grupos sociais, dando maiores subsídios para a permanência do estudante até a conclusão do seu curso.

\section{ACESSO E PERMANÊNCIA DE QUILOMBOLAS NA BAIXADA MARANHENSE: PERFIL E PERCEPÇÕES DE ESTUDANTES DO CAMPUS PINHEIRO /UFMA}

No âmbito da UFMA, existe o Campus de Pinheiro, localizado na Baixada Ocidental Maranhense, o qual foi revitalizado durante o processo de expansão das Universidades Federais. De acordo com dados da Fundação Cultural Palmares, hoje existem mais de 170 comunidades quilombolas nessa região do estado do Maranhão ${ }^{6}$.

Atualmente, esse Campus registra o quantitativo de 1.157 estudantes regularmente matriculados nos cursos presenciais de graduação. Desse total, 255 são assistidos por algum programa de assistência estudantil, sendo que 38 destes são estudantes remanescentes de quilombolas, beneficiários do PBP/MEC (UFMA, 2019).

Para este estudo, optou-se por analisar o perfil básico/acadêmico dos estudantes beneficiários do PBP/MEC no Campus Pinheiro/UFMA, visto que dispomos de informações relacionadas a eles, por meio do serviço de assistência estudantil do campus. Importa citar que, embora haja grandes probabilidades de existência de outros estudantes quilombolas nesse Centro, não constam registros no sistema acadêmico, pois as formas de ingresso contemplam apenas a categoria pretos e pardos, sem especificação ou diferenciação de grupos étnicos, a exemplo de quilombolas. Desse modo, a referência que se tem sobre os estudantes oriundos de comunidades quilombolas no Campus Pinheiro/UFMA limita-se aos controles de concessão de bolsas do PBP/MEC.

\footnotetext{
${ }^{6}$ Dados retirados da Tabela "CERTIDÕES EXPEDIDAS ÀS COMUNIDADES REMANESCENTES DE QUILOMBOS (CRQS) ATUALIZADA ATÉ A PORTARIA No 138/2019, PUBLICADA NO DOU DE 02/08/2019”. Disponível em: http://www.palmares.gov.br/wp-content/uploads/2015/07/certificadas-0208-2019.pdf
} 
Para traço do perfil dos estudantes quilombolas do Campus Pinheiro/UFMA, beneficiários do $\mathrm{PBP} / \mathrm{MEC}$, optou-se por realizar levantamentos por meio do Sistema Integrado de Gestão de Atividades Acadêmicas (SIGAA) da UFMA, tomando-se como base os dados referentes ao primeiro semestre do ano de 2019 .

Entre o ano de 2013 e o $1^{\text {o }}$ semestre de 2019, 38 estudantes quilombolas do Campus Pinheiro/UFMA foram contemplados com o auxílio do PBP/MEC. Desse total, 24 estão com matrícula ativa em curso, sendo que 01 deles está em fase de conclusão; 10 estudantes colaram grau nesse intervalo; e 03 encontram-se em situação de cancelamento por abandono de curso, conforme ilustrado no Gráfico 01.

Gráfico 01: Estudantes quilombolas beneficiários do PBP/MEC no Campus Pinheiro/UFMA, segundo situação de matrícula

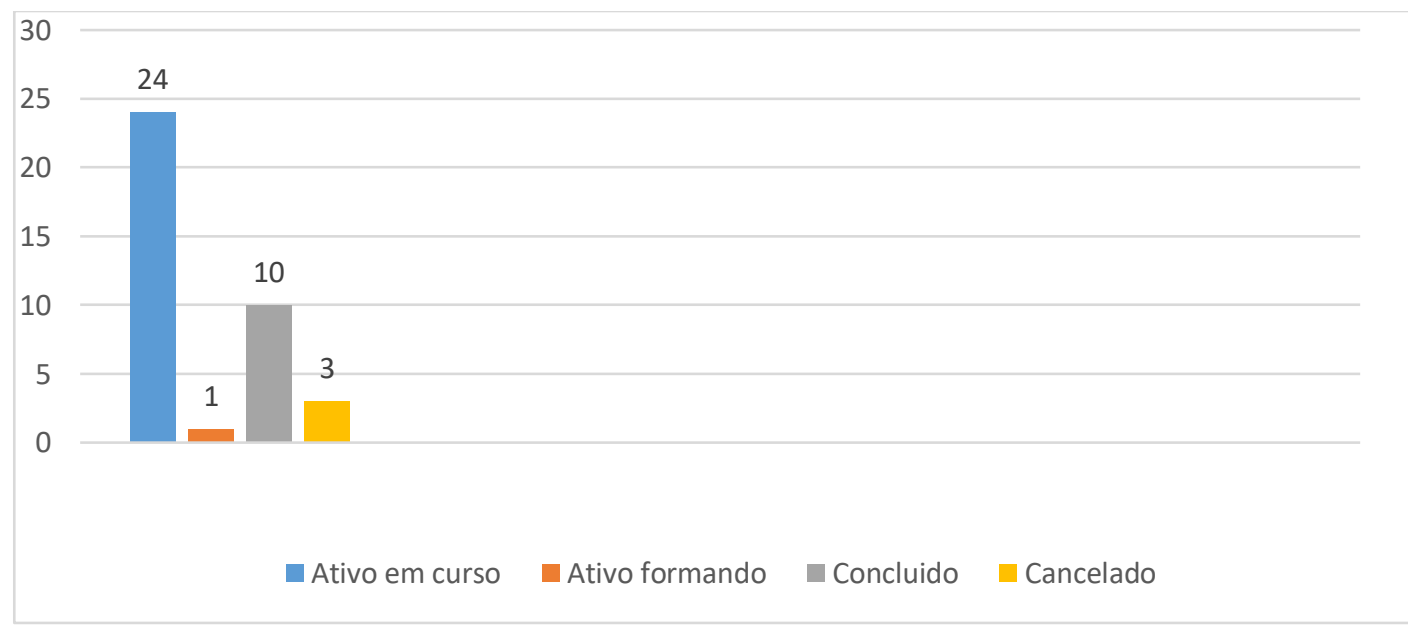

Fonte: Elaborado pelas autoras com base em Relatórios do SIGAA/UFMA (2019).

Estes estudantes são oriundos de comunidades quilombolas autodefinidas e/ou reconhecidas pela Fundação Cultural Palmares, de diversas localidades circunvizinhas da cidade-sede do Campus da Universidade: São Vicente Ferrer, Turilândia, Pedro do Rosário, Peri-Mirim, Palmeirândia, Mirinzal, Bequimão, Santa Helena, Guimarães e São Bento, dentre outras. Cumpre destacar que essas localidades ficam relativamente distantes 
do Campus-sede da Universidade, sem contar que as residências dos estudantes quilombolas estão localizadas em comunidades, na maioria das vezes, bastante afastadas da região central do município. A maioria dos quilombolas faz o trajeto diário de ida e volta, o que se torna cansativo e oneroso; outros optaram em alugar imóveis na cidade de Pinheiro, de modo que fiquem mais perto do campus universitário.

Quanto à autodeclaração de cor/raça, os estudantes quilombolas se identificam no Gráfico 02 da seguinte forma:

Gráfico 02: Estudantes quilombolas beneficiários do PBP/MEC no Campus Pinheiro/UFMA, segundo

Autoidentificação relacionada a cor/raça

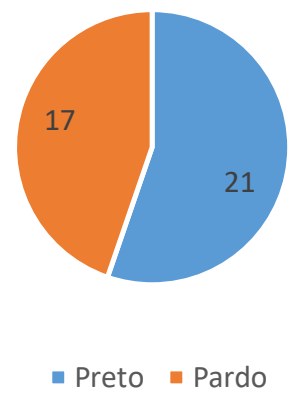

Fonte: Elaborado pelas autoras com base em Relatórios do SIGAA/UFMA (2019).

Baseado na classificação do IBGE, conforme subdivisão da categoria negro, os estudantes se autoidentificam, em sua maioria, como pretos (21) e os demais como pardos (17).

Em relação à faixa etária, estão classificados conforme dados que seguem no Gráfico 03.

Gráfico 03: Estudantes quilombolas beneficiários do PBP/MEC no Campus Pinheiro/UFMA, segundo faixa etária 


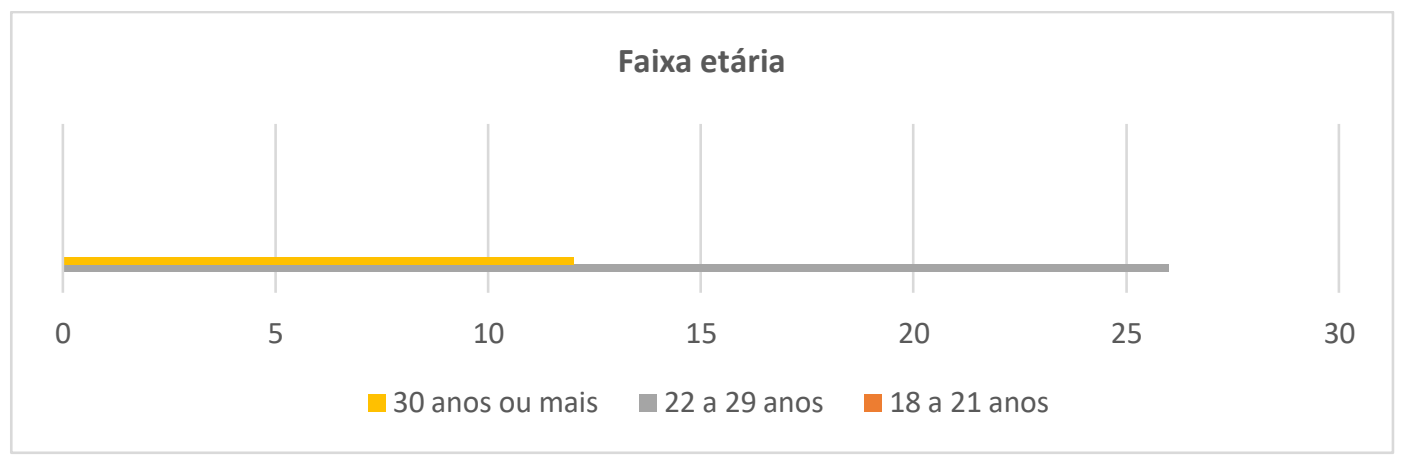

Fonte: Elaborado pelas autoras com base em Relatórios do SIGAA/UFMA (2019).

Os dados sugerem que a política de expansão da educação superior, nesse Centro, tem alcançado tanto jovens estudantes quilombolas como indivíduos que não tiveram acesso aos bancos universitários na faixa etária prevista. Registra-se um número considerável (26) de estudantes quilombolas com idade entre 22 e 29 anos; e com faixa etária entre 30 e 48 , identificam-se 12 estudantes.

Quanto ao estado civil, de acordo com o Gráfico 04, a maioria declara-se solteiro (32). Os casados são em número de 03, e aqueles em situação declarada como outro, também somam 03. Não há registros de divorciados nem viúvos.

Gráfico 04: Estudantes quilombolas beneficiários do PBP/MEC no Campus Pinheiro/UFMA, segundo estado civil

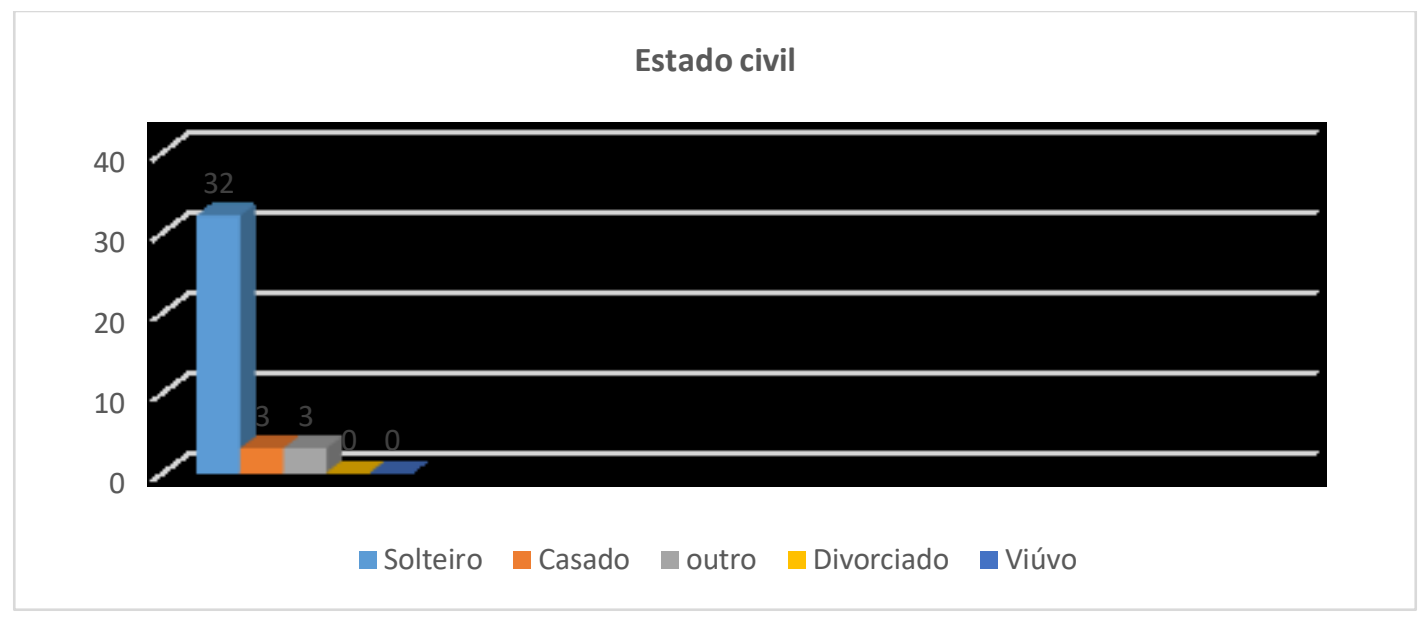

Fonte: Elaborado pelas autoras com base em Relatórios do SIGAA/UFMA (2019).

Em complemento ao Gráfico 03, onde se observa que os quilombolas beneficiários do PBP/MEC do Campus Pinheiro/UFMA pertencem a faixas etárias 
distintas, o Gráfico 04 demonstra que, em sua maioria, são solteiros. Em referência à situação de matrícula e de vinculação ao benefício, percebe-se que o índice de retenção e evasão é quase irrelevante, conforme discriminado no Gráfico 05.

Gráfico 05: Estudantes quilombolas beneficiários do PBP/MEC no Campus Pinheiro/UFMA, segundo situação de vinculação à Bolsa

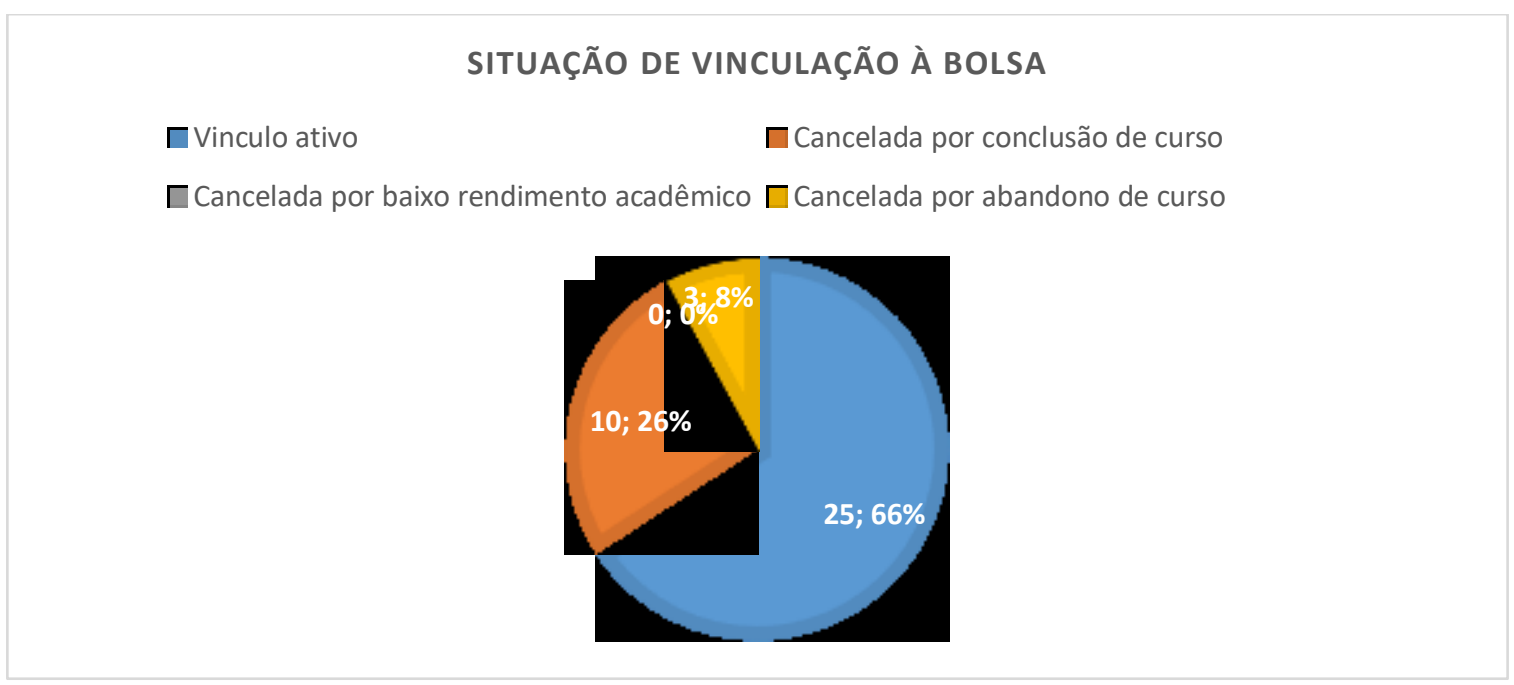

Fonte: Elaborado pelas autoras com base em Relatórios do SIGAA/UFMA (2019).

Em relação à situação de vinculação ao benefício, em 2019, temos no Campus Pinheiro: 25 bolsistas com vínculo ativo; 10 com vínculo cancelado, em função de colação de grau; 03 cancelados por abandono de curso; e nenhum (0) cancelado por baixo rendimento acadêmico. Em termos percentuais, destaca-se que $26 \%$ dos quilombolas beneficiários do PBP/MEC conseguiram concluir com êxito os seus cursos e apenas $8 \%$ encontraram dificuldades para permanecer na Universidade.

\section{- Dados acadêmicos dos beneficiários do PBP no Campus Pinheiro/ UFMA}

Para uma avaliação dos dados acadêmicos, optou-se por ilustrar alguns aspectos importantes. O primeiro deles se refere à origem escolar (Gráfico 06).

Gráfico 06: Estudantes quilombolas beneficiários do $\mathrm{PBP} / \mathrm{MEC}$ no Campus Pinheiro/UFMA, segundo origem escolar 


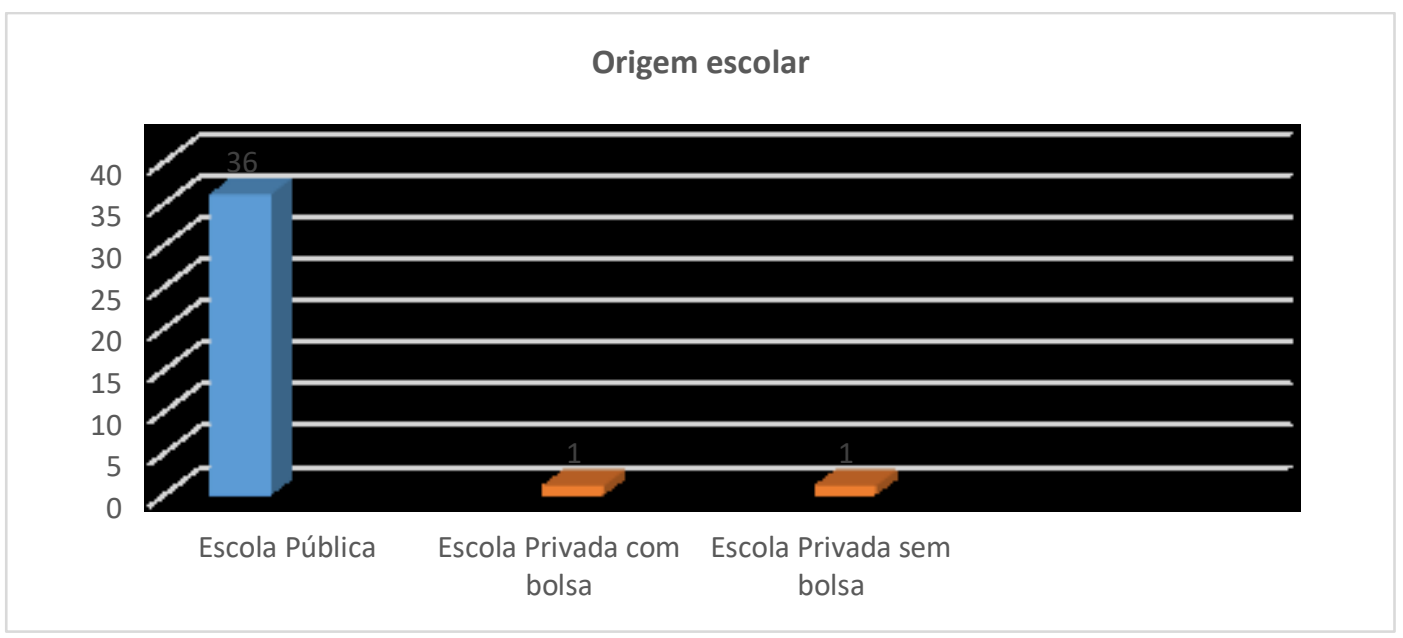

Fonte: Elaborado pelas autoras com base em Relatórios do SIGAA/UFMA (2018).

De acordo com o levantamento realizado por meio do SIGAA, dos 38 beneficiários do PBP/MEC do Campus Pinheiro, 36 são originários de escola pública e apenas 02 concluíram o Ensino Médio em instituição privada, no entanto, 01 na condição de bolsista integral, e o outro, sem bolsa.

O segundo aspecto diz respeito à forma de ingresso. Conforme dados levantados no sistema institucional, observa-se entre os quilombolas, a predominância de três formas de acesso aos cursos de graduação por meio do Sistema de Seleção Unificada (Sisu): Sisu categoria Escola Pública NEGRO (13), Sisu categoria AMPLA CONCORRÊNCIA (11), Sisu Escola Pública NEGRO- Renda Familiar (9), Sisu Escola Pública (4) e Vagas Remanescentes (1), conforme dados contidos no Gráfico 07.

Gráfico 07: Estudantes quilombolas beneficiários do PBP/MEC no Campus Pinheiro/UFMA, segundo forma de ingresso na Universidade

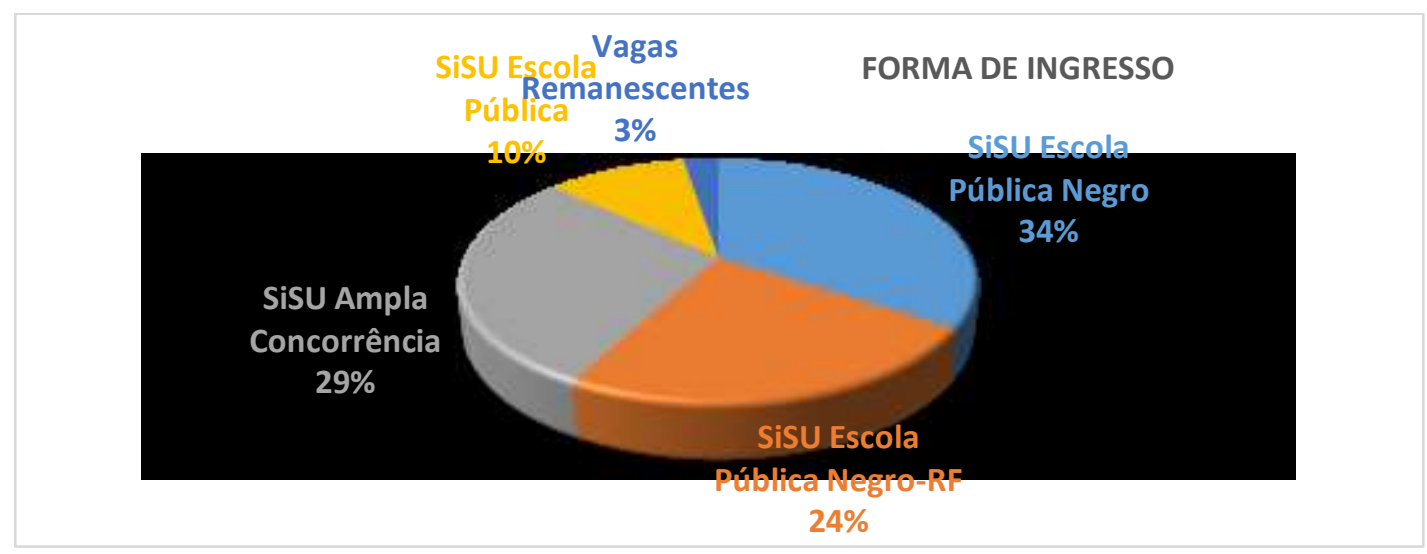


Fonte: Elaborado pelas autoras com base em Relatórios do SIGAA/UFMA (2019).

É possível verificar, por meio dos dados de forma de ingresso, que a maioria dos remanescentes quilombolas beneficiários do PBP nesse Campus entrou pelo sistema de cotas, notadamente a categoria escola pública negro (13), que representa 34\% do total. Juntando as categorias negro - renda familiar e escola pública, há 26 estudantes, ou seja, $68 \%$ do total ocupando vagas reservadas para estudantes oriundos de escola pública. Onze quilombolas (30\%) optaram pela ampla concorrência, categoria que inclui discentes oriundos do ensino privado, o que indica que o ingresso de negros nos cursos de graduação nesse Centro tem ultrapassado o mínimo estabelecido pela política de cotas.

O terceiro aspecto é o curso escolhido. Pela ordem de concentração, o primeiro é o curso de Licenciatura em Ciências Humanas-História (19). Seguem-se os cursos de Licenciatura em Ciências Naturais-Biologia (7), Enfermagem (7), Licenciatura em Ciências Humanas-Filosofia (4) e Licenciatura em Educação Física (1), conforme especificado no Gráfico 08.

Gráfico 08: Estudantes quilombolas beneficiários do PBP/MEC no Campus Pinheiro/UFMA, segundo curso de graduação

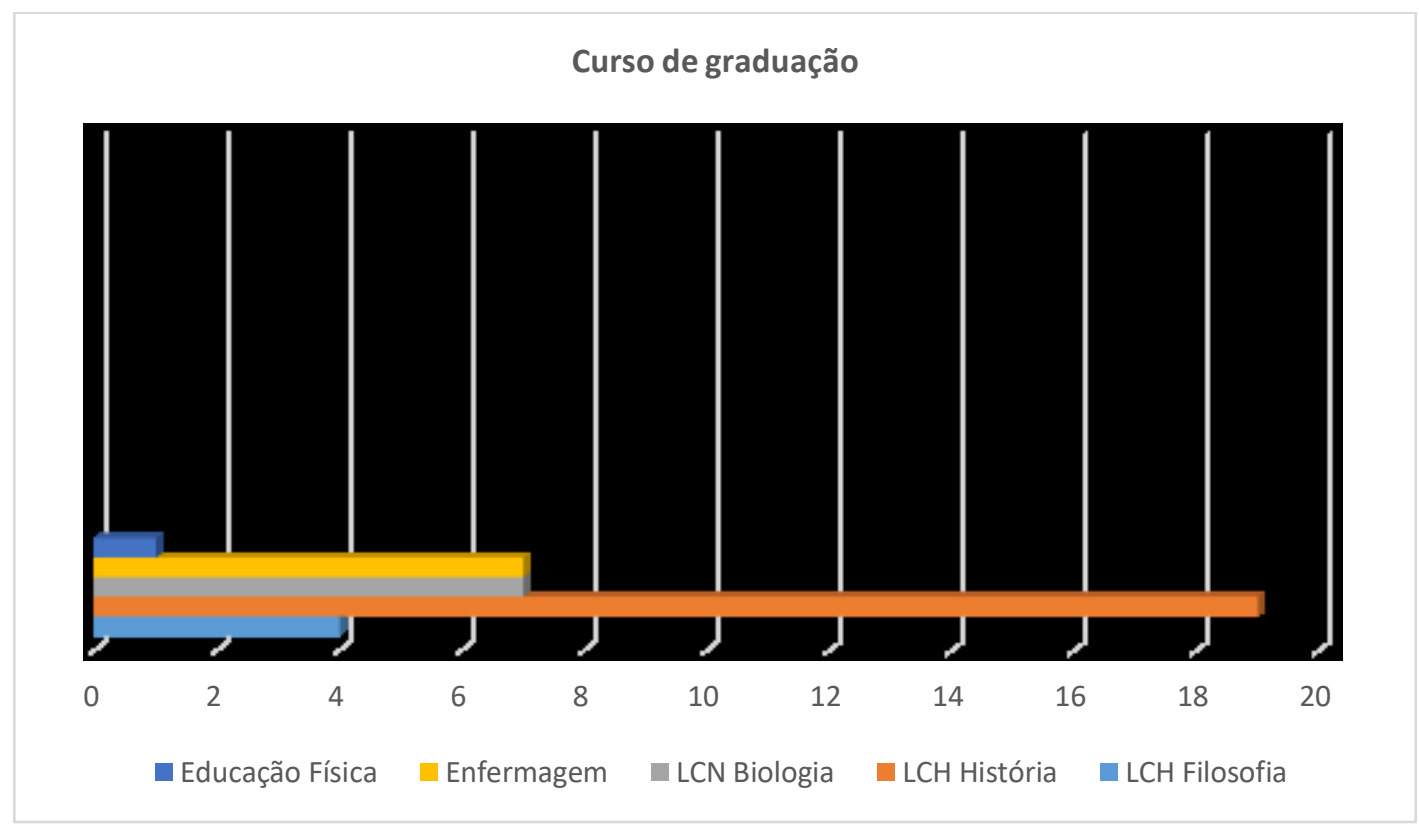

Fonte: Elaborado pelas autoras com base em Relatórios do SIGAA/UFMA (2019). 
Pelo que é possível observar, metade dos remanescentes de quilombos do Campus Pinheiro, beneficiários do PBP, concentram-se no curso de Licenciatura em Ciências Humanas - História, cerca de 50\%. Isso fica evidenciado também em pesquisas (Ristoff, 2014), as quais demonstram que as camadas mais pobres da população brasileira que têm acesso à educação superior encontram-se em cursos menos competitivos e de menor valorização no mercado como as Licenciaturas. Analisando dados de ciclos do ENADE, Ristoff (2014) indica que, apesar da ampliação do acesso de categorias sociais reprimidas, a exemplo dos negros, inclusive em cursos de graduação mais demandados, em cursos como Medicina e Odontologia, essa representação ainda é pequena. Em relação ao Campus Pinheiro/UFMA, especificamente, cabe frisar que não há ainda registros de estudantes quilombolas no curso de Medicina.

O quarto e último aspecto é o rendimento acadêmico, ou seja, o desempenho em termos quantitativos, retratado por meio do Coeficiente de Rendimento (CR), representado no Gráfico 09.

Gráfico 09: Estudantes quilombolas beneficiários do PBP/MEC no Campus Pinheiro/UFMA, segundo Coeficiente de Rendimento (CR)

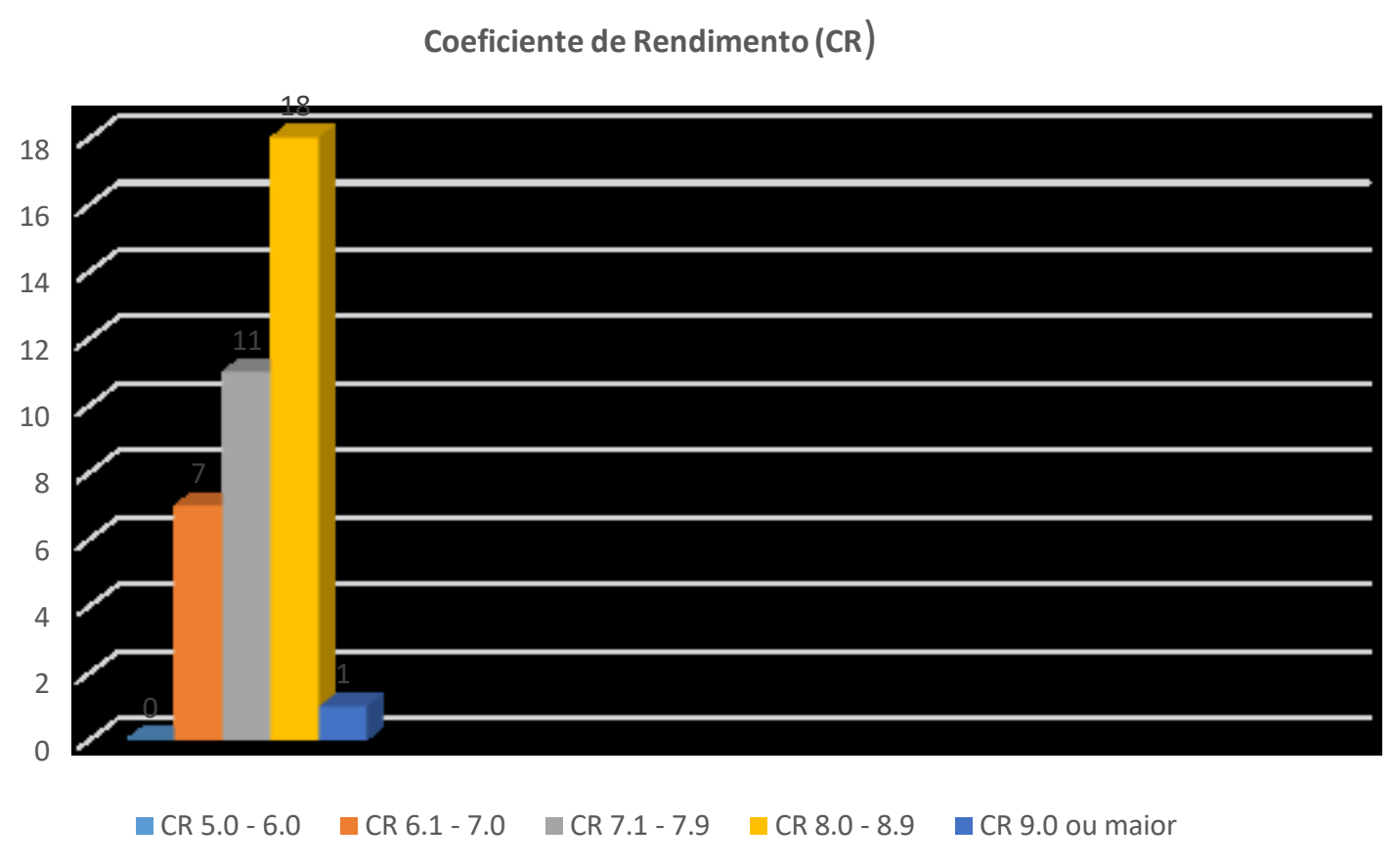

Fonte: Elaborado pelas autoras com base em Relatórios do SIGAA/UFMA (2019). 
Por meio das informações extraídas do SIGAA, verificou-se que estes estudantes mantêm rendimento acadêmico elevado. Dos 38 bolsistas, 18 apresentam/apresentaram Coeficiente de Rendimento entre 8.0 - 8.9. Parcela significativa (11) sustenta o CR entre 7.1 - 7.9. Um beneficiário possui CR maior que 9.0; e 07 deles apresentam baixo rendimento - menor que 7.0. Em termos percentuais, $81 \%$ dos bolsistas PBP do Campus Pinheiro mantêm um CR acima de 7,0.

Numa análise geral dos aspectos acadêmicos, averiguou-se que os estudantes quilombolas do Campus Pinheiro/UFMA, beneficiários do PBP/MEC, ocupam em sua maioria, vagas destinadas às cotas para negros e se concentram nos cursos de Licenciaturas, com destaque na LCH - História. Além disso, os índices de evasão são ínfimos, se comparados aos números referentes ao desempenho acadêmico dos demais estudantes não contidos nas especificidades em foco.

- Percepções de estudantes quilombolas do Campus Pinheiro/UFMA sobre a educação superior e as condições de permanência

Em referência à análise das contribuições do $\mathrm{PBP} / \mathrm{MEC}$ para os beneficiários do Campus Pinheiro/UFMA, optou-se em apresentar fragmentos das respostas obtidas nos questionários como forma de evidenciar as impressões que os sujeitos da pesquisa possuem acerca da educação superior, bem como as dificuldades enfrentadas enquanto estudantes universitários, oriundos de comunidades quilombolas. Reunimos aqui questionários aplicados nos anos de 2017 e 2019.

Questionamos sobre o que representa para eles ter um curso superior, obtivermos respostas como: "Superar obstáculos, vencer preconceitos, ser persistente nas tomadas decisões" (C.S. Questionário aplicado em julho/2019); "Uma realização de um sonho individual e da minha família por ser a primeira pessoa da família a cursar o ensino superior” (J.J.G.L. Questionário aplicado em julho/2019); “O aumento da possibilidade de ascensão social, visto que sou de família carente e aumentaria as chances no mercado de trabalho" (M.M.F.M. Questionário aplicado em julho/2019). Pelo que é possível abstrair dessas respostas, a educação superior representa, além de uma satisfação pessoal, uma expectativa de familiares que não tiveram a mesma oportunidade e também uma possibilidade de ascensão social. 
Outro questionamento buscou verificar se a vivência acadêmica pode contribuir para a comunidade à qual o estudante pertence e de que forma isso ocorre. Algumas respostas: "Sim; com novos conhecimentos, novas atitudes" (C.S. Questionário aplicado em julho/2019); "Sim. Acredito que os conhecimentos apreendidos na academia me possibilitarão a ter futuras pesquisas, no intuito de resgatar a história da comunidade e divulgar a mesma" (J.J.G.L. Questionário aplicado em julho/2019); “Sim, pretendo depois de formado ser professor na minha comunidade e possibilitar aos jovens a visão da importância de querer progredir através da educação, sobretudo na educação superior" (M.M.F.M. Questionário aplicado em julho/2019). Nesses posicionamentos, observa-se não só uma visão para além da própria formação, mas também uma vontade de difundir os conhecimentos adquiridos e incentivar outros jovens a progredirem nos estudos e mudarem sua realidade.

Acerca das dificuldades enfrentadas para que pudessem permanecer durante toda a sua formação no curso e concluí-lo com êxito, eles apontaram fatores como desigualdade, preconceitos e discriminação, dentro e fora do espaço acadêmico, além de outras dificuldades de ordem de condições objetivas e de logística:

O percurso da minha cidade Turilândia até o Campus de Pinheiro, pois enfrento todos os dias mais de $100 \mathrm{~km}$ de ida e volta o que se torna muito cansativo (C.C. Questionário aplicado em agosto/2017).

A principal dificuldade é ter que pagar transporte muito caro para chegar até a universidade devido à prefeitura não disponibilizar ônibus (J.C. Questionário aplicado em agosto/2017).

A principal dificuldade no início do curso foi ter que pagar transporte muito caro para chegar até a universidade. Uma outra dificuldade foi em compreender determinados conteúdos referentes à disciplina de Física e Química, devido não ter cursado um Ensino Médio de qualidade, principalmente no meu caso que fiz Telecurso, sem um professor regular em sala de aula (E.C. Questionário aplicado em agosto/2017).

A primeira dificuldade é o aprendizado, pois entramos na universidade com o ensino médio defasado tendo que encarar assunto desconhecido e não conseguir acompanhar o que o professor passa (E.B. Questionário aplicado em agosto/2017).

Sustento financeiro, conciliar a vida de estudante e de trabalhador, deslocamento do interior para a cidade (E.M. Questionário aplicado em agosto/2017).

Uma das principais seria a distância que o estudante percorre para chegar à universidade. Além das atividades fora do ambiente acadêmico. Não deixando de salientar as criações de novos campus próximos a essas comunidades e até o 
preconceito sofrido pelos descendentes, pela sua origem (J.J.G.L. Questionário aplicado em julho/2019).

As dificuldades descritas envolvem questões relacionadas à distância das suas comunidades/municípios em relação à sede do campus da universidade; os altos custos com transporte para o deslocamento diário; necessidade de conciliar estudo com trabalho. Além dessas, junta-se a dificuldade de compreender e acompanhar os conteúdos, considerando as fragilidades vivenciadas na Educação Básica, o que sugere a importância de uma assistência pedagógica que leve em conta essa problemática. Nesse sentido, “acompanhar as proporções e condições de chegada da juventude negra ao nível terciário fornece indicadores importantes para a avaliação de todo o fluxo escolar da educação básica" (Lazaro, Cerqueira e Castro, 2019, p. 301).

No tocante à importância do PBP para continuidade de estudos na universidade, foram elencadas, pelos estudantes quilombolas, como principais despesas: custos com alimentação, transporte, materiais escolares, cópias, impressões e compra de livros. Neste sentido, todos os respondentes apontaram o auxílio financeiro do PBP/MEC como primordial no atendimento das necessidades citadas.

Está sendo muito importante, tendo em vista que tenho participação na ajuda financeira da minha família e se eu não tivesse o auxílio não teria como eu investir na minha vida acadêmica, uma vez que tudo é muito dispendioso, transporte, alimentação, e recursos materiais diversos voltados para a academia e ao magistério que estou me formando (M.M.F.M. Questionário aplicado em julho/2019).

Só estou na universidade cursando o ensino superior graças ao Programa Bolsa Permanência. Através do benefício pago o transporte e todas as outras despesas que tenho na universidade (C.C. Questionário aplicado em agosto/2017).

Está sendo de fundamental importância pelo fato desse benefício me ajudar a pagar o transporte que chega no valor de 400,00 reais mensal. Se não fosse essa bolsa não estaria hoje na universidade, pois antes eu trabalhava contratada pela prefeitura do município e dava para pagar, porem fiquei desempregada e não tinha como pagar o transporte. Além disso tem como tirar xerox dos materiais passados pelos professores e comer no RU (E.C. Questionário aplicado em agosto/2017).

Com o dinheiro eu pago transporte e tiro a xerox e quando tem evento fora da universidade uso para pagar as despesas (E.B. Questionário aplicado em agosto/2017). 
O Bolsa Permanência MEC foi de suma importância para mim. Pois esse auxílio permitiu que eu concluísse o curso (M.S. Questionário aplicado em agosto/2017).

O auxílio do programa está sendo muito importante para encaminhar meus estudos na universidade. Desde ao se pensar no deslocamento do interior para a cidade, o estudante quilombola daí já enfrenta dificuldade, pois se não tivesse esse auxílio, seria bem apertado custear as despesas na universidade e em casa. Além disso, tenho mais tempo para me dedicar somente aos estudos, tendo assim um maior rendimento acadêmico (E.M. Questionário aplicado em agosto/2017).

Observa-se nas respostas dos estudantes remanescentes de quilombos que as dificuldades encontradas para cursar uma graduação estão sendo contornadas por meio do auxílio financeiro do PBP/MEC. Eles apontaram despesas elevadas com deslocamento e necessidade de dedicação aos estudos. Consideram ainda que, muito provavelmente, teriam abandonado o curso, caso não fossem assistidos pelo programa.

Quanto aos aspectos a serem melhorados no PBP/MEC, sugerem:

$\mathrm{O}$ acesso às oportunidades, ter mais projetos voltados às comunidades, etc. (M.M.F.M. Questionário aplicado em julho/2019).

Uma maior divulgação do programa, pois muitos estudantes quilombolas não têm conhecimento do programa (B.F Questionário aplicado em agosto/2017).

Deveriam incentivar em pesquisas nas próprias comunidades (E.C. Questionário aplicado em agosto/2017).

Nas políticas de intervenção com as comunidades onde os discentes fazem parte, para fazer trabalhos voltados à universidade e comunidades quilombolas. Ex: projetos, registro com fotos e filmagem e o mapeamento dos locais em documentário (E.B. Questionário aplicado em agosto/2017).

As observações relacionadas à melhoria do $\mathrm{PBP} / \mathrm{MEC}$, destacadas por estes beneficiários, concorrem no sentido de haver uma maior divulgação do programa nas IFES, pois muitos outros estudantes universitários que fazem jus ao benefício, não têm acesso às informações e muitas vezes acabam abandonando o curso pela falta de condições financeiras para nele permanecer e concluí-lo com êxito.

Outro aspecto levantado foi a respeito da possibilidade dos estudantes quilombolas serem incentivados, na forma de condição para concessão do auxílio, a realizarem projetos e pesquisas que evidenciem e valorizem suas comunidades de origem. 


\section{CONSIDERAÇÕES FINAIS}

No Brasil, historicamente, o acesso à universidade foi restrito a uma elite dominante. Aos jovens oriundos de grupos sociais desfavorecidos, a exemplo de negros e quilombolas, esse ingresso tem sido limitado diante de realidades objetivas que dificultam não apenas o ingresso, mas também a permanência destes estudantes na educação superior. Uma das questões de maior destaque nas pautas reivindicatórias do Movimento Negro é a luta pela escolarização da população negra, a qual, durante um longo período, foi excluída dos bancos escolares. Essa reivindicação sempre foi central, entendendo-se a educação, segundo Gomes (2011), como um importante meio de produção de conhecimento, o qual contribui para a formação de quadros intelectuais e políticos. Sem contar que educação é condição para concorrer a funções e cargos públicos ou privados, sendo o nível de instrução usado como critério de inclusão ou exclusão no mundo do trabalho.

No tocante aos povos quilombolas, que representam a contínua luta e resistência negra por igualdade de direitos e preservação da cultura, as condições de acesso e permanência à educação superior adquirem ainda mais centralidade.

No Campus Pinheiro/UFMA, especificamente, registra-se o total de 38 estudantes (incluindo ativos, formados, formandos e evadidos) originários de comunidades remanescentes de quilombolas dos municípios circunvizinhos que são/foram atendidos pelo PBP/MEC (UFMA, 2019). Dadas às especificidades destas comunidades e a participação destes jovens na educação superior, é salutar investigar como vem se dando o processo de inclusão destes estudantes na Universidade, identificando limites e possibilidades desta política de permanência.

As análises indicaram que as medidas de expansão e interiorização da UFMA tem favorecido o ingresso de estudantes quilombolas no Campus lócus desse estudo, especialmente em cursos de Licenciatura. Esses jovens são, em maioria, oriundos do ensino público, sendo que alguns deles são os primeiros da família a ingressarem na educação superior.

No tocante à permanência, as trajetórias na Universidade são marcadas por desafios de ordem acadêmica, socioeconômica e de assistência estudantil que dificultam a continuidade dos estudos e conclusão do curso. Todavia, a partir dos estudos e dados 
coletados, observou-se baixos percentuais de evasão e elevado Coeficiente de Rendimento (CR) dos bolsistas; o que sugere que o auxílio financeiro concedido a estes, mesmo numa perspectiva assistencialista, tem cumprido o objetivo proposto.

Cabe ressaltar que os dados se referem apenas aos beneficiados pelo Programa Bolsa Permanência do MEC, não alcançando outros estudantes quilombolas que vivem e vivenciam os desafios que se apresentam a esses discentes na educação superior. No contexto de cortes progressivos do orçamento das universidades públicas e que atingem as atividades de ensino, pesquisa, extensão e assistência estudantil dessas instituições, a permanência dos estudantes quilombolas na educação pública, assim como de demais minorias sociais, também é comprometida.

\section{REFERÊNCIAS}

BRASIL. Decreto $n^{0}$ 6.096, de 24 de abril de 2007. Institui o Programa de Apoio a Planos de Reestruturação e Expansão das Universidades Federais - REUNI. Diário Oficial da União, Brasília, DF, 25 abr. 2007. Disponível em: <http://www.planalto.gov.br/ccivil 03/ ato20072010/2007/decreto/d6096.html $>$.

BRASIL. Decreto $n^{\circ} 7.234$, de 19 de julho de 2010. Dispõe sobre o Programa Nacional de Assistência Estudantil - PNAES. Diário Oficial da União, Brasília, DF, 20 jul. 2010. Disponível em: <http://www.planalto.gov.br/ccivil_03/_ato2007-2010/2010/decreto/d7234.htm>.

BRASIL. Fundação Cultural Palmares. Certidões Expedidas às Comunidades Remanescentes de Quilombos (CRQS) atualizadas até a Portaria $n^{0}$ 194/2017, publicada no DOU de 04/07/2017. Disponível em: < http://www.palmares.gov.br/wpcontent/uploads/2017/07/CERTID\%C3\%95ESEXPEDIDAS\%C3\%80SCOMUNIDADESREMANESCENTES-DE-QUILOMBOS-04-07-2017.pdf>.

BRASIL. Lei ${ }^{\circ} 12.711$, de 29 de agosto de 2012. Dispõe sobre o ingresso nas universidades federais e nas instituições federais de ensino técnico de nível médio e dá outras providências. Diário Oficial da União, Brasília, DF, 30 ago. 2012 (2012a). Disponível em: $<$ http://www.planalto.gov.br/ccivil 03/ ato2011-2014/2012/lei/112711.htm $>$.

BRASIL. Manual de Gestão do Programa de Bolsa Permanência. Brasília: SESU / SETEC MEC, 2013. Disponível em: http://permanencia.mec.gov.br/docs/manual.pdf

BRASIL. Ministério da Educação. MEC assina convênios para expandir universidades. Brasília, DF, MEC: Imprensa, 2005. Disponível em: $<$ http://portal.mec.gov.br/component/content/article?id=5236:sp-186802867>

BRASIL. Ministério da Educação. Análise sobre a Expansão das Universidades Federais 2003 a 2012. Brasília, 2012b. Disponível em: < http://portal.mec.gov.br/index.php?option=com docman\&view=download\&alias $=12386$ analise-expansao-universidade-federais-2003-2012-pdf\&Itemid $=30192>$. 
BRASIL. Ministério da Educação. MEC e Inep divulgam dados do Censo da Educação Superior 2016. Brasília, DF, MEC: Imprensa, 2017. Disponível em: $<$ http://portal.inep.gov.br/artigo//asset_publisher/B4AQV9zFY7Bv/content/id/854595>

BRASIL. Ofício-Circular $n^{\circ}$ 2/2016/DIPES/SESU/SESU-MEC, de 11 de maio de 2016. Disponível em : < $<$ http://prae.ufsc.br/files/2016/05/Of\%C3\%ADcio-Circular-n\%C2\%BA2-2016DIPES-SESU-SEST-MEC.pdf>.

CAMPOS, Laís Rodrigues. Do quilombo à universidade: trajetórias, relatos, representações e desafios de estudantes quilombolas da Universidade Federal do Pará-Campus Belém quanto à permanência. 2016. 133 f. Dissertação (Mestrado) - Universidade Federal do Pará, Instituto de Ciências da Educação, Belém, 2016. Programa de Pós-Graduação em Educação.

DIAS SOBRINHO, José. Democratização, qualidade e crise da educação superior: faces da exclusão e limites da inclusão. Educação e Sociedade. vol.31 nº. 113. Campinas, Out./Dez. 2010.

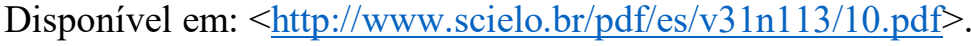

FERES JR.; João; DAFLON, Verônica Toste. Políticas da Igualdade Racial no Ensino Superior. CADERNOS DO DESENVOLVIMENTO FLUMINENSE, 2015.

GOMES, Nilma Lino. Diversidade étnico-racial, inclusão e equidade na educação brasileira: desafios, políticas e práticas. RBPAE, Goiânia, v. 7, n. 1, jan./abr. 2011, p. 109-121.

LÁZARO, André; CERQUEIRA, Luciano; CASTRO, Carolina. MOVIMENTOS EM MOVIMENTO NA AGENDA DA EDUCAÇÃO. Revista da Associação Brasileira de Pesquisadores/as Negros/as (ABPN), [S.1.], v. 11, n. Ed. Especi, p. 297-320, maio 2019. ISSN 2177-2770. Disponível

em: $<$ http://abpnrevista.org.br/revista/index.php/revistaabpn1/article/view/694> $>$. Acesso em: 01 ago. 2019.

HONORATO, Gabriela, VARGAS, Hustana; HERINGER, Rosana. Assistência estudantil e permanência na universidade pública: refletindo sobre os casos da UFRJ e da UFF.Trabalho publicado nos Anais no $38^{\circ}$ Encontro Anual da ANPOCS,2014.

RISTOFF, Dilvo. O novo perfil do campus brasileiro: uma análise do perfil socioeconômico do estudante de graduação. Avaliação, Campinas; Sorocaba, SP, v. 19, n. 3, p. 723-747, nov. 2014.

UFMA. Relatório de Gestão 2016. UFMA, São Luís, 2017a.

UFMA. Relatório de Ingressos de alunos - Campus Pinheiro. SIGAA/UFMA. 2019.

Recebido em: 30/09/2019

Aceito em: 30/11/2019 